\title{
Substituent effect on the ground- and excited-state torsional motions of pentiptycene-derived 1,4-bis(phenylethynyl)benzenes
}

\author{
Jye-Shane Yang a,*, Jyu-Lun Yan ${ }^{\mathrm{b}}$, Kang-Ling Liau ${ }^{\mathrm{b}}$, Hui-Hsu Gavin Tsai ${ }^{\mathrm{b}}$, Chung-Yu Hwang ${ }^{\mathrm{b}}$ \\ a Department of Chemistry, National Taiwan University, Taipei 10617, Taiwan \\ b Department of Chemistry, National Central University, Chungli 32001, Taiwan
}

\section{A R T I C L E I N F O}

\section{Article history:}

Available online $\mathrm{xxx}$

Dedicated to Professor Haruo Inoue on the occasion of his 60th birthday.

\section{Keywords:}

Torsional barrier

Pentiptycene

Planarization

p-Phenyleneethynylene

\begin{abstract}
A B S T R A C T
The electronic absorption and emission spectra and fluorescence lifetimes of four pentiptycene-derived 1,4-bis(phenylethynyl)benzenes 2-5 and three segments of $\mathbf{2}$ (i.e., compounds $\mathbf{6}-\mathbf{8}$ ) in MTHF at a variety of temperature between 80 and $300 \mathrm{~K}$ are reported. Compound $\mathbf{2}$ is an ethynylene-bridged pentiptycene trimer with octyloxy substituents at the two terminals. Compounds $\mathbf{3}-\mathbf{5}$ differ from $\mathbf{2}$ only in the middle ring, which is a triptycene (3), a tetramethylphenylene (4), or the parent phenylene group (5). Despite the different ground-state conformer distribution in solutions, there is only a small difference in fluorescence properties for 2-5 at room temperature due to fast excited-state planarization reaction. However, in the solvent glass at low temperatures the planarization reaction is restricted with an extent depending on the middle-ring substituents. The well-resolved spectra and decay times for the planar and the twisted conformers of $\mathbf{2}$ allow one to deduce the excited-state planarization barrier $(3.0 \mathrm{kcal} / \mathrm{mol})$ and the overall phenylene torsional barrier $(8.5 \mathrm{kcal} / \mathrm{mol})$. These values are larger than those $(0.47$ and $3.54 \mathrm{kcal} / \mathrm{mol}$, respectively) predicted by the AM1 and ZINDO/S calculations. The similarities in photophysical behavior between the twisted form of $\mathbf{2}$ and the model compounds $\mathbf{7}$ and $\mathbf{8}$ suggest that the former possesses large dihedral angles between the central and either one or both of the neighboring phenylene rings. Our results provide the first experimental approach toward the evaluation of the excited-state torsional barrier for the $p$-phenyleneethynylene systems.
\end{abstract}

(C) 2009 Published by Elsevier B.V.

\section{Introduction}

Poly( $p$-phenyleneethynylene)s (PPEs) are rigid rod-shaped and highly fluorescent $\pi$-conjugated systems that have found great utilities in the construction of ultra-sensitive fluorescent chemosensors [1-7] and blue light-emitting materials [7-10]. To understand the intrinsic intrachain conformation effect on the fluorescence properties, model compounds such as diphenylacetylene [11-13], 1,4-bis(phenylethynyl)benzene (1) [14-19], and the longer oligomers [19-25] have been extensively investigated. The results of theoretical studies have suggested that in both the ground $\left(\mathrm{S}_{0}\right)$ and the lowest singlet excited-state $\left(\mathrm{S}_{1}\right)$ the energy minimum and maximum correspond to the planar and the orthogonally twisted geometry (e.g., 1-coplanar vs 1-twisted-a, Scheme 1), respectively $[15,18,19]$. However, the much larger phenylene torsional energy in $\mathrm{S}_{1}$ vs $\mathrm{S}_{0}$ leads to a larger band gap for the twisted vs the planar form. More precisely, the torsional barrier in $S_{0}$ is lower than $1 \mathrm{kcal} / \mathrm{mol}$, indicating the presence of a continuum of rotational conformers, but in $S_{1}$ the barrier is as high as $10 \mathrm{kcal} / \mathrm{mol}$ for 1 on the basis of the

\footnotetext{
* Corresponding author. Tel.: +8862 3366 1649; fax: +886223636359.

E-mail address: jsyang@ntu.edu.tw (J.-S. Yang).
}

AM1 and ZINDO calculations. Such a deep and smooth excited-state potential energy surface would drive all the excited twisted conformers (e.g., 1-twisted-a and 1-twisted-b) toward the planar form in unconstrained media, which accounts for the observation of only a single emitting species [17,21]. Recent computational studies have confirmed that coupling of the torsional motions to the electronic excitation dominates the spectroscopic features [24,25]. In addition, substitutions on the phenylene rings could significantly affect the torsional barrier in the $S_{0}$ and/or $S_{1}$ states $[13,19]$. Nonetheless, to date the corresponding experimental evaluation of the excitedstate torsional barrier is void due to the lack of either well-resolved absorption spectra for the planar vs the twisted conformers or direct fluorescence information about the twisted transition structures.

We have recently shown that introduction of the bulky iptycene substituents to each of the phenylene groups of $\mathbf{1}$ (i.e., the pentiptycene derivative $\mathbf{2}$ ) not only perturbs the potential energy surface but also creates local minima for the twisted conformers in both the $S_{0}$ and $S_{1}$ states [26]. The resulting activated excited-state planarization process could then be inhibited at low temperatures (i.e., $130 \mathrm{~K}$ or lower), and thus the photophysical data of two distinct conformers (or conformer domains) of $\mathbf{2}$ were independently obtained. Although the exact conformations of the two fluorescing species were not identified, the data suggested that one is located 


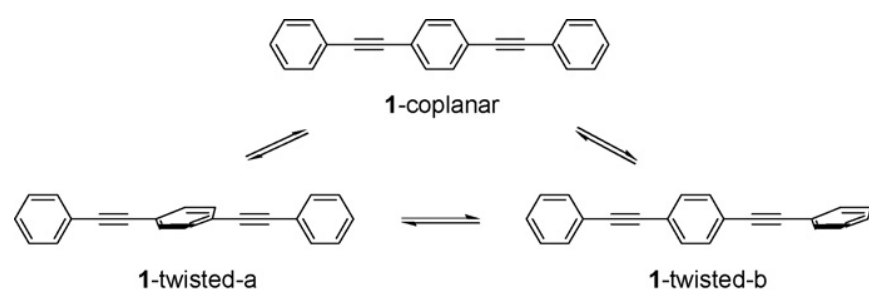

Scheme 1.

near the excited-state global minimum (we refer it to the "planar" form, although it might not be completely coplanar) and the other possesses large dihedral angles between neighboring phenylene rings (the twisted form). As compared to the planar form, the twisted one displays blue-shifted absorption and emission, comparable fluorescence quantum yield, and longer lifetimes. Since the planarization reaction is the only activated singlet state decay process for the twisted form, the planarization barrier $\left(E_{\mathrm{a}}\right)$ might be determined from nonlinear fitting of its temperature-dependent singlet lifetimes using Eq. (1) [27,28]:

$\tau_{\mathrm{f}}(T)=\frac{1}{\left[\Sigma k+A \exp \left(-E_{\mathrm{a}} / R T\right)\right]}$

where $\Sigma k$ is the sum of all nonactivated processes (fluorescence and intersystem crossing), and $A$ and $E_{\mathrm{a}}$ are the preexponential and activation energy, respectively, for the activated process. This method has been successfully employed in a variety of aryl substituted alkenes to retrieve the activation parameters for the $\mathrm{C}=\mathrm{C}$ torsions [27-29]. In conjunction with the 0-0 transition energies for both the planar ( $\left.E_{00, \text { planar }}\right)$ and the twisted ( $\left.E_{00 \text {, twisted }}\right)$ forms and the ground-state energy difference for the twisted vs the planar form $\left(E_{\mathrm{pt}}\right)$, the excited-state torsional barrier $\left(E_{\mathrm{a}}^{*}\right)$ on going from the planar to the twisted form can be experimentally evaluated (Fig. 1) on the basis of Eq. (2):

$E_{\mathrm{a}}^{*}=E_{\mathrm{a}}+E_{00, \text { twisted }}+E_{\mathrm{pt}}-E_{00, \text { planar }}$

Provided that the dihedral angle in the twisted form is close to $90^{\circ}$, the barrier $E_{\mathrm{a}}^{*}$ would correspond to the overall torsional barrier in $\mathrm{S}_{1}$.

With the above-mentioned strategy in mind, we have carried out an investigation of the temperature-dependent absorption and fluorescence spectra and singlet lifetimes of $\mathbf{2}$ and three related compounds (3-5, Chart $\mathbf{1})$, where the size of substituents in the

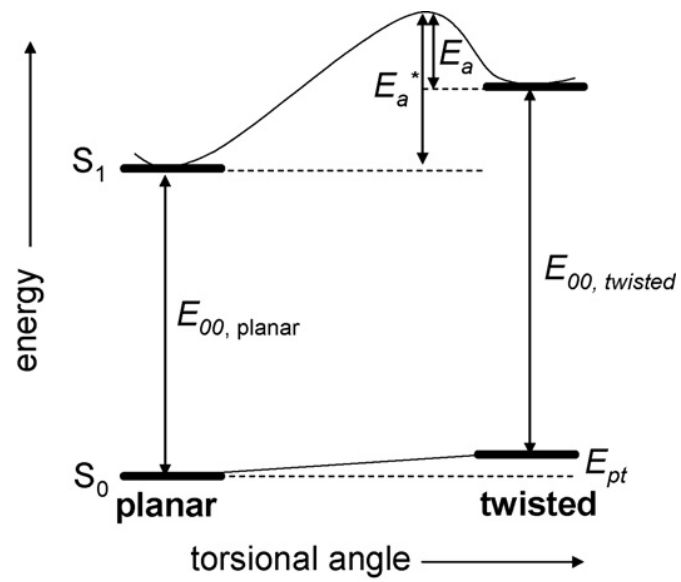

Fig. 1. An approach toward experimental evaluation of the phenylene torsional barrier $\left(E_{\mathrm{a}}^{*}\right)$ of 1,4-bis(phenylethynyl)benzenes in the lowest singlet excited-state $\left(S_{1}\right)$ through the determination of the $0-0$ transition energies for the planar and the twisted conformers ( $E_{00}$, planar and $\left.E_{00 \text {, twisted }}\right)$ and the planarization barrier $\left(E_{\mathrm{a}}\right)$. The ground-state energy difference $\left(E_{\mathrm{pt}}\right)$ between the planar and the twisted conformers can be estimated through AM1 calculations. middle ring is reduced. To gain more information on the twisted form of $\mathbf{2}$, the corresponding studies on its segments $\mathbf{6 - 8}$ have also been performed. In conjunction with AM1 and ZINDO calculations, our results reported herein show that reducing the bulkiness of the middle-ring substituents lowers the excited-state planarization barrier but not necessarily the overall torsional barrier. The determined excited-state torsional barrier for $\mathbf{2}$ is approximately $8.5 \mathrm{kcal} / \mathrm{mol}$ in 2-methyltetrahydrofuran (MTHF), providing the first experimental evaluation of the excited-state torsional barrier for $p$-phenyleneethynylene $\pi$-conjugated systems.

\section{Experimental}

\subsection{Synthesis}

Solvents for organic synthesis were reagent grade or HPLC grade, but all were HPLC grade for spectra and quantum yield measurements. MTHF was dried by sodium metal and distilled before use. All other compounds were purchased from commercial sources and were used as received. Analytical TLC was performed on commercial Merck plates coated with silica gel $60 F_{254}$. For flash chromatography Merck Silica gel Si $60(0.0603-0.2000 \mathrm{~mm})$ was employed. The synthesis of $\mathbf{2}$ and $\mathbf{6 - 8}$ has been reported $[4,26]$ and that of $\mathbf{3 - 5}$ is outlined in Scheme 2 with $\mathbf{6}$ as the common starting material. The Sonogashira coupling reactions between 6 and the corresponding diiodoarenes afforded the desired 1,4bis(phenylethynyl)benzenes 3-5. Whereas both 1,4-diiodobenzene and 2,3,5,6-tetramethyl-1,4-diiodobenzene are commercially available, the 2,5-diiodotriptycene (9) was prepared according to the method reported in the literature [30]. A typical procedure for the Sonogashira coupling reaction represented by the case of $\mathbf{3}$ is shown below and followed by the structural characterization data of 3-5.

Compound 3. A mixture of $6(0.05 \mathrm{~g}, 0.09 \mathrm{mmol}), 9(0.02 \mathrm{~g}$, $0.04 \mathrm{mmol}), \mathrm{Pd}\left(\mathrm{PPh}_{3}\right)_{4},(0.02 \mathrm{~g}, 0.02 \mathrm{mmol}), 10 \mathrm{~mL}$ of benzene, and $5 \mathrm{~mL}$ of diisopropylamine was heated to $85^{\circ} \mathrm{C}$ for $24 \mathrm{~h}$ under argon. The solution was cooled and then diluted with $\mathrm{CH}_{2} \mathrm{Cl}_{2}$. The residue was filtered off and the filtrate was concentrated under reduced pressure. Column chromatography with $\mathrm{CH}_{2} \mathrm{Cl}_{2}$ /hexane $(1: 2)$ as the eluent afforded the white solid of compound 3 with a yield of $89 \%$. mp: $>350{ }^{\circ} \mathrm{C} ;{ }^{1} \mathrm{H} \mathrm{NMR}\left(400 \mathrm{MHz}, \mathrm{CDCl}_{3}\right): 0.99(\mathrm{t}, J=6.8 \mathrm{~Hz}$, $6 \mathrm{H}$ ), $1.42-1.56(\mathrm{~m}, 16 \mathrm{H}), 1.73$ (quin, $J=7.6 \mathrm{~Hz}, 4 \mathrm{H}$ ), $2.08(\mathrm{tt}, J=7.6$ and $6.8 \mathrm{~Hz}, 4 \mathrm{H}), 4.05(\mathrm{t}, J=6.8 \mathrm{~Hz}, 4 \mathrm{H}), 5.79(\mathrm{~s}, 4 \mathrm{H}), 6.13(\mathrm{~s}, 4 \mathrm{H})$,

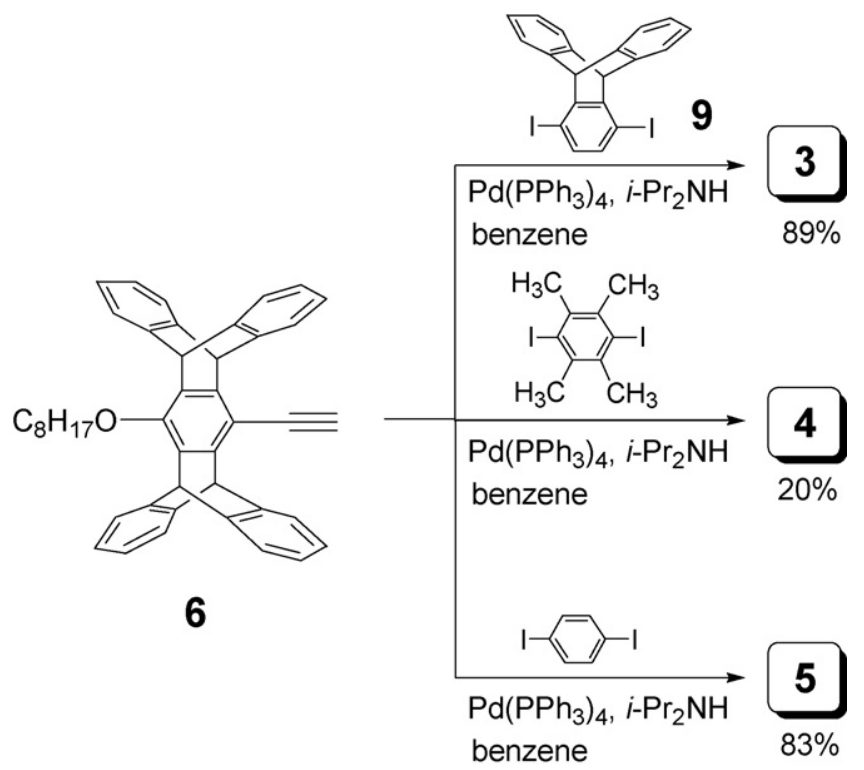

Scheme 2. 


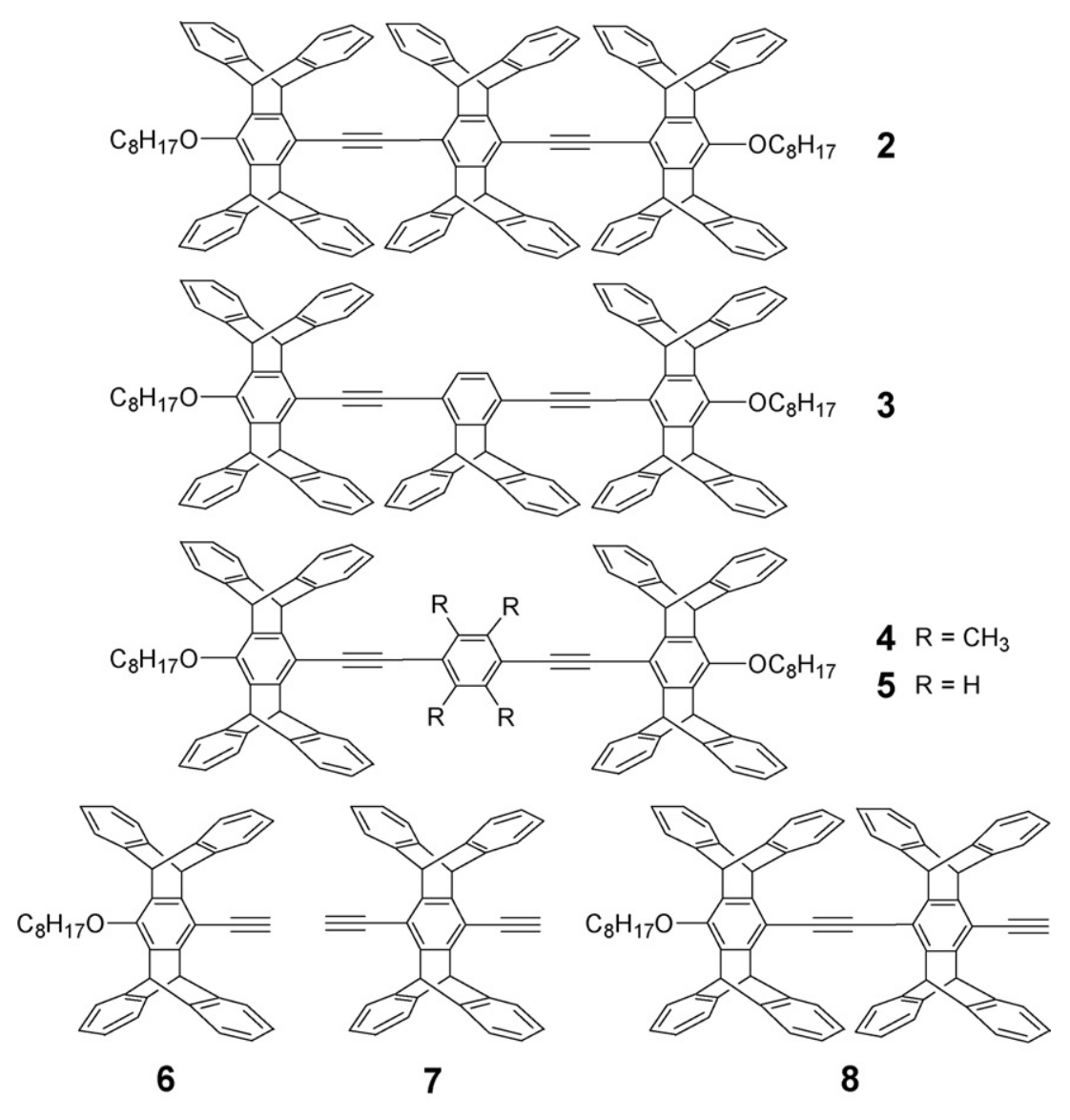

Chart 1.

$6.52(\mathrm{~s}, 2 \mathrm{H}), 7.01-7.06(\mathrm{~m}, 16 \mathrm{H}), 7.18-7.20(\mathrm{~m}, 4 \mathrm{H}), 7.40-7.42(\mathrm{~m}$, $8 \mathrm{H}), 7.52-7.54(\mathrm{~m}, 8 \mathrm{H}), 7.57(\mathrm{~s}, 2 \mathrm{H}), 7.72-7.74(\mathrm{~m}, 7 \mathrm{H}) \mathrm{ppm} ;{ }^{13} \mathrm{C}$ NMR (100 MHz, $\left.\mathrm{CDCl}_{3}\right): 14.2,22.7,26.4,29.4,29.6,30.6,30.9,32.0$, $48.4,52.6(2 \mathrm{C}), 89.9,92.3,110.9,119.2,123.6,123.9,124.2,125.4(2 \mathrm{C})$, 125.9, 128.3, 135.7, 144.8, 145.1(2C), 146.0, 147.4, 150.1 ppm; IR (KBr): 3067, 2925, 2853, 1713, 1458, 1299, $1278 \mathrm{~cm}^{-1}$; FAB-HRMS calcd for $\mathrm{C}_{108} \mathrm{H}_{86} \mathrm{O}_{2}: 1414.6628$, found: 1414.6614 .

Compound 4. mp: $>350{ }^{\circ} \mathrm{C} ;{ }^{1} \mathrm{H}$ NMR $\left(500 \mathrm{MHz}, \mathrm{CDCl}_{3}\right): 0.95(\mathrm{t}$, $J=6.5 \mathrm{~Hz}, 6 \mathrm{H}), 1.38-1.55(\mathrm{~m}, 16 \mathrm{H}), 1.67$ (quin, $J=7.6 \mathrm{~Hz}, 4 \mathrm{H}), 2.02(\mathrm{tt}$, $J=7.6$ and $6.5 \mathrm{~Hz}, 4 \mathrm{H}), 2.97(\mathrm{~s}, 12 \mathrm{H}), 3.98(\mathrm{t}, J=6.5 \mathrm{~Hz}, 4 \mathrm{H}), 5.72(\mathrm{~s}$, $4 \mathrm{H}), 6.01(\mathrm{~s}, 4 \mathrm{H}), 6.94-7.02(\mathrm{~m}, 16 \mathrm{H}), 7.34-7.35(\mathrm{~m}, 8 \mathrm{H}), 7.37-7.39$ $(\mathrm{m}, 8 \mathrm{H}) \mathrm{ppm} ;{ }^{13} \mathrm{C} \mathrm{NMR}\left(125 \mathrm{MHz}, \mathrm{CDCl}_{3}\right): 14.2,19.2,22.7,26.4,29.4$, 29.6, 30.6, 30.9, 31.9, 48.3, 52.6, 93.7, 94.5, 111.6, 123.5, 123.9, 124.2, 125.3(2C), 135.5, 135.9, 145.0, 145.2, 145.7, 149.7 ppm; IR (KBr): 3065, 2924, 2853, 1713, 1460, 1300, $1275 \mathrm{~cm}^{-1}$; FAB-HRMS calcd for $\mathrm{C}_{98} \mathrm{H}_{86} \mathrm{O}_{2}$ : 1294.6628 , found: 1294.6643 .

Compound 5. mp: $>350{ }^{\circ} \mathrm{C} ;{ }^{1} \mathrm{H}$ NMR $\left(500 \mathrm{MHz}, \mathrm{CDCl}_{3}\right): 0.97(\mathrm{t}$, $J=6.7 \mathrm{~Hz}, 6 \mathrm{H}$ ), $1.39-1.56(\mathrm{~m}, 16 \mathrm{H}), 1.69$ (quin, $J=7.6 \mathrm{~Hz}, 4 \mathrm{H}), 2.03$ (tt, $J=7.6$ and $6.7 \mathrm{~Hz}, 4 \mathrm{H}), 3.99(\mathrm{t}, J=6.7 \mathrm{~Hz}, 4 \mathrm{H}), 5.72(\mathrm{~s}, 4 \mathrm{H}), 5.92$ (s, 4H), 6.96-7.01 (m, 16H), 7.34-7.36 (m, 8H), 7.43-7.45 (m, 8H), 7.91 (s, 4H) ppm; ${ }^{13} \mathrm{C}$ NMR (125 MHz, $\left.\mathrm{CDCl}_{3}\right): 14.2,22.7,26.4,29.4$, 29.6, 30.6, 31.9, 48.3, 52.5, 87.2, 94.5, 110.7, 123.5, 123.7, 124.0, $125.2,125.3,131.9,135.5,145.0,145.1,146.0,150.0$ ppm; IR (KBr): $3068,2926,2851,2357,1457,1298,1272 \mathrm{~cm}^{-1}$; FAB-HRMS calcd for $\mathrm{C}_{94} \mathrm{H}_{78} \mathrm{O}_{2}$ : 1238.6002 , found: 1238.5980 .

\subsection{Spectral measurements}

${ }^{1} \mathrm{H}$ and ${ }^{13} \mathrm{C}$ NMR spectra were recorded in $\mathrm{CDCl}_{3}$ solution using Bruker DRX-400 or DRX-500 spectrometers with the chloroform $\left({ }^{1} \mathrm{H}: \delta 7.24 \mathrm{ppm} ;{ }^{13} \mathrm{C}: \delta 77.00 \mathrm{ppm}\right)$ peaks as internal standards.
Infrared spectra were recorded on a Nicolet MAGNA-IR 550 spectrometer. Mass spectra were collected by the Instrumentation Center of National Central University. UV-vis absorption spectra were obtained using a Cary 300 double-beam spectrophotometer. Fluorescence spectra were recorded on an Edinburgh FLS920 spectrometer and corrected for the response of the detector. A $\mathrm{N}_{2}$-bubbled solution of anthracene in hexane $\left(\Phi_{\mathrm{f}}=0.27\right)$ [31] was used as a standard for the fluorescence quantum yield determinations of 2-8 under ambient atmosphere with solvent refractive index correction. The optical density of all solutions was about 0.1 at the wavelength of excitation, and an error of $\pm 10 \%$ is estimated for the fluorescence quantum yields. Fluorescence decays of 2-8 under ambient atmosphere were measured by means of an Edinburgh FLS920 spectrometer with a gated hydrogen arc lamp, using a scatter solution to profile the instrument response function. The goodness of the nonlinear least-squares fit was judged by the reduced $\chi^{2}$ value ( $<1.2$ in all cases), the randomness of the residuals, and the autocorrelation function. The temperature-dependent absorption and fluorescence spectra and fluorescence decays were measured in an Oxford OptistatDN cryostat with an ITC502 temperature controller. AM1 [32] and ZINDO [33] calculations were preformed on a PC cluster using the algorithms supplied with the package of Gaussian 03 revision B.02, a product of Gaussian Inc. [34].

\section{Results and discussion}

\subsection{Gas-phase rotational potentials}

The structures of compounds $\mathbf{2 - 5}$ differ only in the substituents of their middle phenylene rings. Whereas the middle phenylene ring is a bulky pentiptycene group in $\mathbf{2}$, it is a triptycene in $\mathbf{3}$, 
(a)
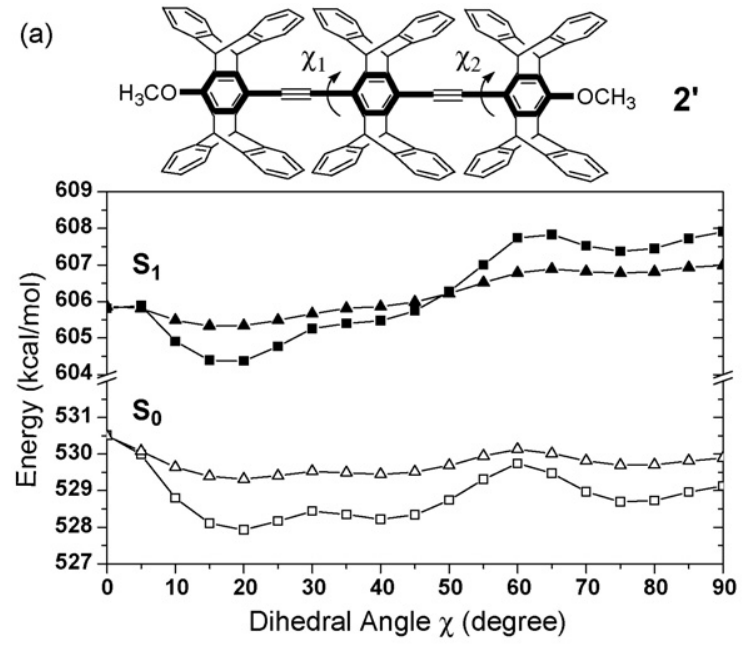

(c)
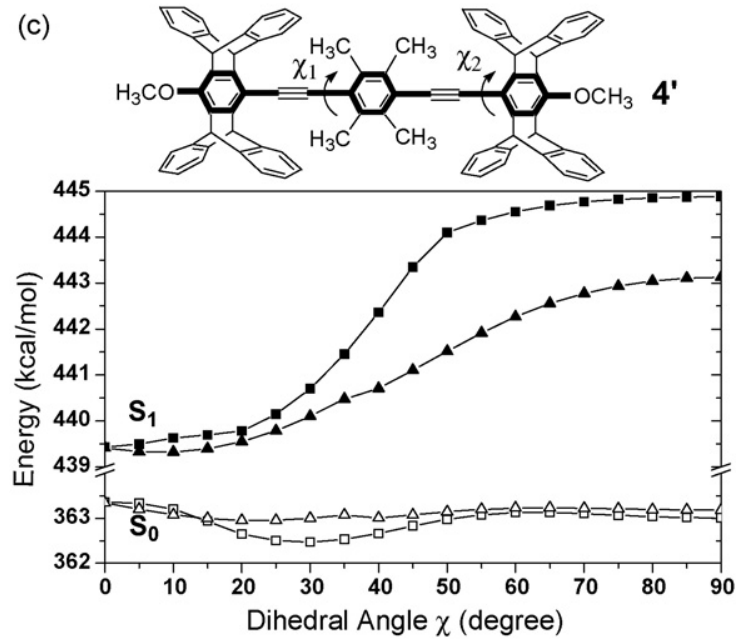

(b)

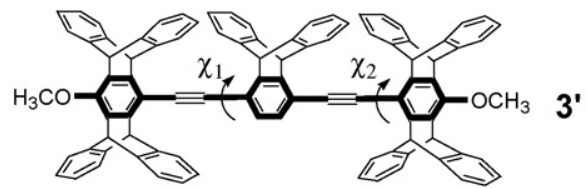

\section{$3^{\prime}$}

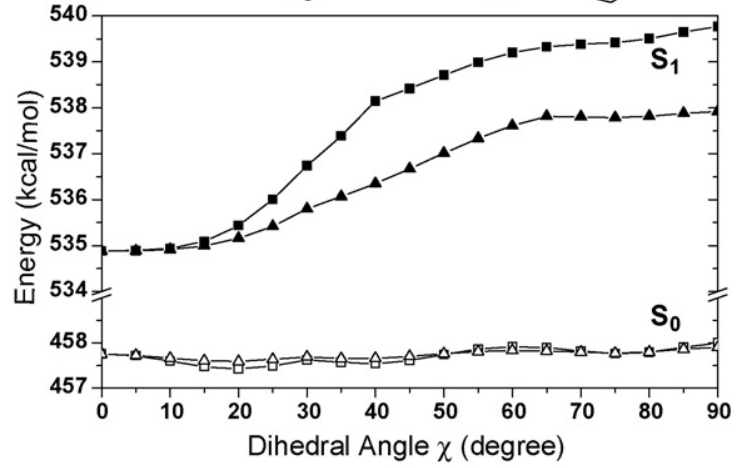

(d)
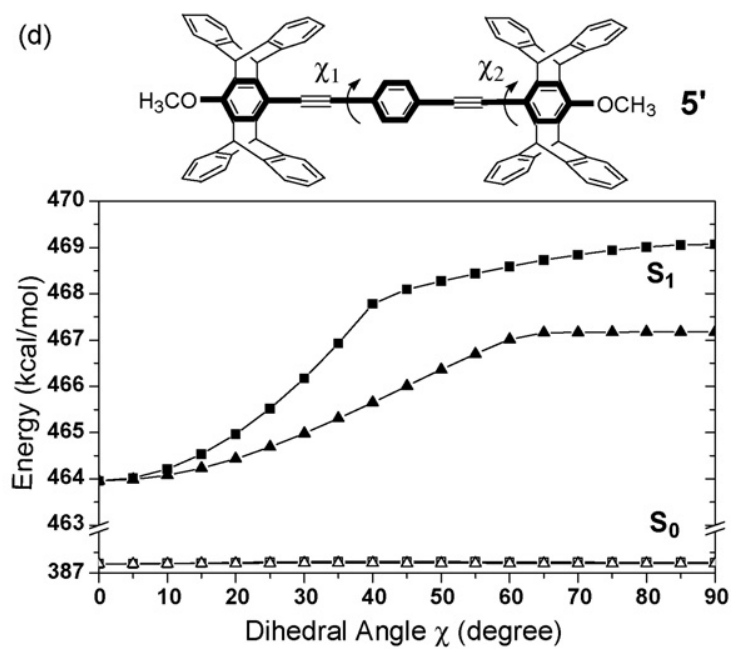

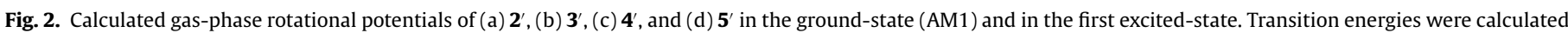
with the ZINDO algorithm. Curves of square and triangle symbols correspond to the central $\left(\chi_{1}\right)$ and the external-ring $\left(\chi_{2}\right)$ rotations.

a tetramethylphenylene in $\mathbf{4}$, and a parent phenylene in $\mathbf{5}$. Substituents can affect the electronic nature of the $\pi$-conjugated 1,4-bis(phenylethynyl)benzene backbone through both electronic and steric interactions. As a result, both factors should be taken into account in discussing the differences in photophysical properties among 2-5.

To gain preliminary information on the effect of substituents on the rotational potentials of $\mathbf{2 - 5}$ in the ground and excited states, calculations based on the AM1 and ZINDO algorithms have been performed. To expedite the calculations, the terminal octyl groups were replaced by methyl groups, and the corresponding compounds were named $\mathbf{2}^{\prime}-\mathbf{5}^{\prime}$ [35]. The rotational potential of $\mathbf{2}^{\prime}-\mathbf{5}^{\prime}$ in $\mathrm{S}_{0}$ was calculated in two different situations: namely, either the central-ring or the external-ring torsions (Fig. 2). For the case of central-ring torsion, the two external conjugated phenylene rings was maintained coplanar while constraining the dihedral angle $\left(\chi_{1}\right)$ formed by the central aryl group to various increments of $5^{\circ}$ from the coplanar $\left(\chi_{1}=0^{\circ}\right)$ to the perpendicular $\left(\chi_{1}=90^{\circ}\right)$ form. The same strategy applies to the external-ring torsion $\left(\chi_{2}=0-90^{\circ}\right)$ by maintaining the other two neighboring phenylene rings (i.e., the central and the other external rings) coplanar. The excited-state potential was built by adding the ZINDO-derived vertical excitation energies to the ground-state potential. It should be noted that the potential energy surface for dihedral angles between $90^{\circ}$ and $180^{\circ}$ would be a mirror image of that from $0^{\circ}$ to $90^{\circ}$, and so on for further rotations due to the symmetric molecular struc- tures in $\mathbf{2}^{\prime}-\mathbf{5}^{\prime}$. The results suggest that reducing the bulkiness of the middle ring results in a flatter potential energy surface in $S_{0}$ and a smoother surface in $\mathrm{S}_{1}$. In addition, the central-ring rotation encounters a larger barrier than the external-ring rotation in both $S_{0}$ and $S_{1}$. For example, in the case of $\mathbf{2}^{\prime}$, the barrier for the central- vs external-ring torsion is $2.59 \mathrm{vs} 1.17 \mathrm{kcal} / \mathrm{mol}$ in $S_{0}$ and 3.54 vs $1.66 \mathrm{kcal} / \mathrm{mol}$ in $\mathrm{S}_{1}$. Apparently, the neighboring pentiptycene-pentiptycene interactions play an important role in the rotational potentials, and the more of such interactions leads to larger torsional barriers. It should also be noted that only $\mathbf{2}^{\prime}$ out of $\mathbf{2}^{\prime}-\mathbf{5}^{\prime}$ was calculated to possess an excited-state local minimum in the twisted region, and thus a more efficient planarization reaction is expected for 3-5. The calculated ground-state central-ring torsional barrier is in the order $\mathbf{2}^{\prime}(2.59 \mathrm{kcal} / \mathrm{mol})>\mathbf{4}^{\prime}$ $(0.89 \mathrm{kcal} / \mathrm{mol})>\mathbf{3}^{\prime}(0.58 \mathrm{kcal} / \mathrm{mol})>\mathbf{5}^{\prime}(0.065 \mathrm{kcal} / \mathrm{mol})$. In contrast, the calculated excited-state central-ring torsional barrier is the lowest for $\mathbf{2}^{\prime}$ and in the order $\mathbf{4}^{\prime}(5.45 \mathrm{kcal} / \mathrm{mol})>\mathbf{5}^{\prime}(5.11 \mathrm{kcal} / \mathrm{mol})>\mathbf{3}^{\prime}$ $(4.88 \mathrm{kcal} / \mathrm{mol})>2^{\prime}(3.54 \mathrm{kcal} / \mathrm{mol})$.

\subsection{Photophysical properties}

Fig. 3 shows the normalized absorption spectra of $\mathbf{2 - 5}$ in hexane and MTHF at room temperature. While broad absorption bands are observed for all cases, the spectra for $\mathbf{2}$ are apparently more structured and somewhat narrower than those for 3-5. Previous studies [26] on $\mathbf{2}$ have suggested that the vibrational band at $354 \mathrm{~nm}$ 


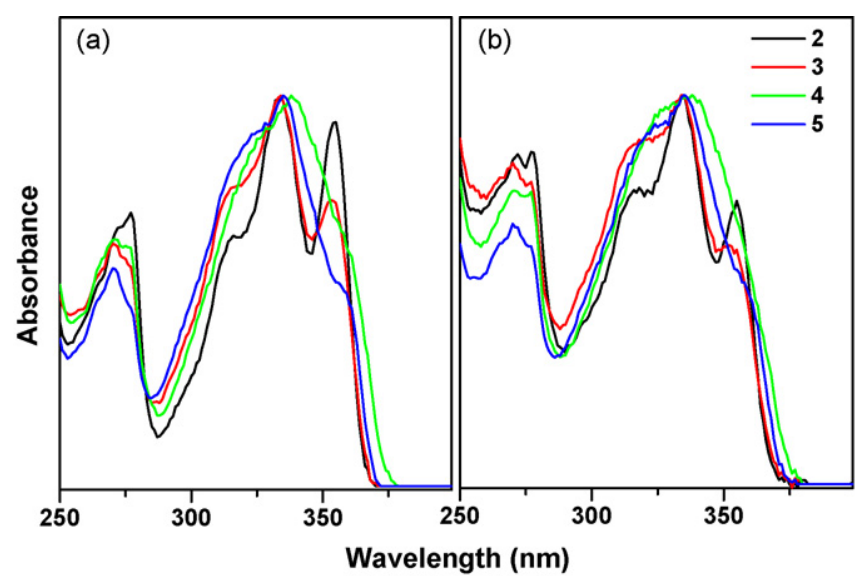

Fig. 3. Normalized absorption spectra of 2-5 in (a) hexane and (b) MTHF.

corresponds to the $0-0$ transition of the planar conformers, because this band mirrors the $0-0$ fluorescence band recorded at room temperature. The absorption band at $333 \mathrm{~nm}$, which is of higher intensity and blue-shifted by ca. $20 \mathrm{~nm}$ as compared to the 354-nm band, is more likely from a coincidental overlapping of the $0-1$ transition of the planar form and the $0-0$ transition of the twisted form, as the vibronic spacing observed in the fluorescence spectrum of the former and the difference in the $0-0$ fluorescence bands for the two different forms are both ca. $20 \mathrm{~nm}$ (vide infra). Like the case of $\mathbf{2}$, the 354-nm band is significant for $\mathbf{3}$ in hexane but it becomes vague in MTHF. In contrast, the absorption profiles for $\mathbf{4}$ and $\mathbf{5}$ in both hexane and MTHF do not have a resolved band near $354 \mathrm{~nm}$, which resembles that of $\mathbf{1}$ in cyclohexane [17]. The latter is known to have a nearly flat ground-state potential energy surface and thus a continuum of conformers. Since the 354-nm band results from the planar conformers, spectra of low intensity around $354 \mathrm{~nm}$ should indicate a low population of the planar conformers. Indeed, recent computational fittings of the observed absorption spectra for a series of alkyl substituted $p$-phenyleneethynylene (PE) oligomers, which possess a rotational potential similar to $\mathbf{1}, \mathbf{4}$, and $\mathbf{5}$, have revealed that the population of conformers for the trimer system builds up at a dihedral angle around $45^{\circ}$ rather than $0^{\circ}$ (the coplanar form) due to the entropy effect [25]. Our calculated results (Fig. 2) are also qualitatively consistent with the relative shape of absorption spectra, since a flatter ground-state potential energy surface would lead to a wider distribution of rotational conformers and less population of the planar form. Thus, the distinct spectral features for $\mathbf{2}$ as compared to $\mathbf{1}, \mathbf{4}$, and $\mathbf{5}$ clearly show that the interactions between the neighboring bulky pentiptycene groups significantly perturb the ground-state conformer distribution. Regarding the solvent effect,

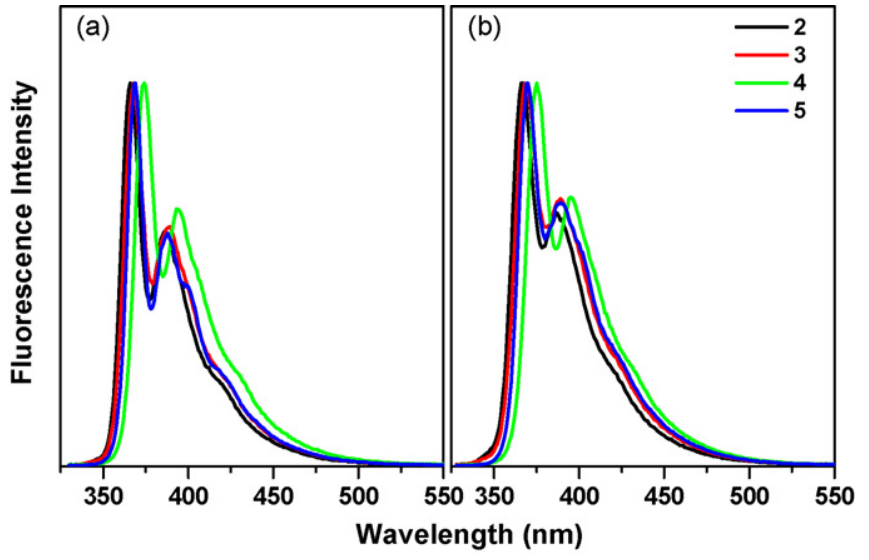

Fig. 4. Normalized fluorescence spectra of 2-5 in (a) hexane and (b) MTHF.

the relative intensity for the 354-nm vs 334-nm band decreases on going from hexane to MTHF for $\mathbf{2}$ and 3, but an opposite trend, albeit to a less extent, is found for $\mathbf{4}$ and $\mathbf{5}$. Evidently, the groundstate conformer distribution is solvent-dependent, and the solvent effect in turn depends on the substituents.

Fig. 4 shows the normalized fluorescence spectra of 2-5 in hexane and MTHF. Unlike the structureless absorption spectra in some cases, all the fluorescence spectra display vibrational structures. In addition, the spectral profiles of $\mathbf{2 - 5}$ in the same solvent are rather similar. In conjunction with the monoexponential fluorescence decay times for all cases, a single emitting species for 2-5 at room temperature is indicated. Previous studies on 1, 2, and the related PE oligomers have suggested that the emitting species should be the planarized conformers due to fast excited-state torsional relaxation $[17,21,26]$.

Table 1 reports the maxima of absorption $\left(\lambda_{\text {abs }}\right)$ and fluorescence $\left(\lambda_{\mathrm{fl}}\right)$, fluorescence decay times $\left(\tau_{\mathrm{fl}}\right)$, and fluorescence quantum yields $\left(\Phi_{\mathrm{fl}}\right)$ for $\mathbf{2}-\mathbf{5}$ in hexane and MTHF at room temperature (ca. $296 \mathrm{~K}$ ). There is only a small variation in the absorption (333-337 nm) and fluorescence maxima (366-375 nm) among 2-5, having $\mathbf{2}$ and $\mathbf{4}$ located at the lower and the higher limits, respectively. Similar situation is also found for their fluorescence quantum yields: namely, the difference in $\Phi_{\mathrm{fl}}$ is small (0.63-0.82), and the values for $\mathbf{2}$ and $\mathbf{4}$ correspond to the lower and the upper values, respectively. The fluorescence lifetimes are essentially the same for all cases $(0.71 \pm 0.06 \mathrm{~ns})$ in terms of the resolution of our apparatus $(\sim 0.1 \mathrm{~ns})$. The resulting fluorescence rate constant $\left(k_{\mathrm{fl}}=\Phi_{\mathrm{fl}} / \tau_{\mathrm{fl}}\right)$ is in the order of $\sim 1 \times 10^{9} \mathrm{~s}^{-1}$ for all four compounds.

We also found that the fluorescence quantum yield but not the fluorescence spectrum is excitation wavelength $\left(\lambda_{\text {ex }}\right)$-dependent, and larger yields are observed when the excitation is at longer

Table 1

Photophysical data of compounds 2-5 in hexane (Hex) and 2-methyltetrahydrofuran (MTHF) at room temperature (ca. $296 \mathrm{~K}$ ).

\begin{tabular}{|c|c|c|c|c|c|}
\hline Compound & Solvent & $\lambda_{\mathrm{abs}}(\mathrm{nm})^{\mathrm{a}}$ & $\lambda_{\mathrm{fl}}(\mathrm{nm})$ & $\tau_{\mathrm{fl}}(\mathrm{ns})^{\mathrm{b}}$ & $\Phi_{\mathrm{fl}}^{\mathrm{b}, \mathrm{c}}$ \\
\hline 2 & $\begin{array}{l}\text { Hex } \\
\text { MTHF }\end{array}$ & $\begin{array}{l}333(354) \\
334(354)^{d}\end{array}$ & $\begin{array}{l}366(387) \\
366(387)^{d}\end{array}$ & $\begin{array}{l}0.74 \\
0.65^{d}\end{array}$ & $\begin{array}{l}0.66 \\
0.63^{\mathrm{d}}(0.73)\end{array}$ \\
\hline 3 & $\begin{array}{l}\text { Hex } \\
\text { MTHF }\end{array}$ & $\begin{array}{l}332(354) \\
335(354)\end{array}$ & $\begin{array}{l}368(389) \\
369(388)\end{array}$ & $\begin{array}{l}0.71 \\
0.74\end{array}$ & $\begin{array}{l}0.72 \\
0.71(0.83)\end{array}$ \\
\hline 4 & $\begin{array}{l}\text { Hex } \\
\text { MTHF }\end{array}$ & $\begin{array}{l}337 \\
337\end{array}$ & $\begin{array}{l}374(395) \\
375(395)\end{array}$ & $\begin{array}{l}0.75 \\
0.76\end{array}$ & $\begin{array}{l}0.82 \\
0.74(0.84)\end{array}$ \\
\hline 5 & $\begin{array}{l}\text { Hex } \\
\text { MTHF }\end{array}$ & $\begin{array}{l}335 \\
335\end{array}$ & $\begin{array}{l}369(388) \\
370(388)\end{array}$ & $\begin{array}{l}0.73 \\
0.77\end{array}$ & $\begin{array}{l}0.77 \\
0.75(0.91)\end{array}$ \\
\hline
\end{tabular}

\footnotetext{
a The second vibronic band or shoulder is given in parentheses.

b Excitation wavelength is $338 \mathrm{~nm}$.

c The values given in parentheses are determined with excitation at $355 \mathrm{~nm}$.

d From ref. [26].
} 
wavelength (Table 1). For example, the $\Phi_{\mathrm{fl}}$ values for 2 in MTHF are 0.63 and 0.73 with the $\lambda_{\text {ex }}$ being 338 and $355 \mathrm{~nm}$, respectively. Since the shorter is the $\lambda_{\text {ex }}$, the more is the twisted conformers excited, the decreased fluorescence quantum yield with 338 vs $355 \mathrm{~nm}$ might suggest that additional nonradiative decays occur for the twisted conformers during the planarization process. We previously compared the fluorescence quantum yield of the planar and the twisted conformers by using the value of $\Phi_{\mathrm{fl}}=0.63$ for the former and argued that the former is slightly weaker in fluorescence than the latter [26]. With the more appropriate value of $\Phi_{\mathrm{fl}}=0.73$ for the planar form, we should conclude that the planar form is somewhat stronger in fluorescence than the twisted form. On the basis of the stronger phosphorescence recorded for the twisted vs the planar form at $80 \mathrm{~K}$ (vide infra), we could ascribe the planarization-induced nonradiative decay to intersystem crossing. It is known that structural twisting could facilitate spin-orbit coupling in $\mathrm{S}_{1}$ and thus the intersystem crossing toward the triplet excited states [27,28].

\subsection{Torsional barriers}

As outlined by Fig. 1 and Eq. (2), to experimentally deduce the excited-state phenylene torsional barrier $E_{\mathrm{a}}^{*}$, we need to know about the planarization barrier $E_{\mathrm{a}}$, the individual 0-0 transition energy for both the planar and the twisted form ( $E_{00}$, planar and $\left.E_{00, \text { twisted }}\right)$, and their ground-state energy difference $E_{\mathrm{pt}}$. The planarization barrier could be derived on the basis of Eq. (1) provided that the lifetimes of the twisted forms can be obtained over a reasonable range of the investigated temperatures. The $0-0$ transition energies could be obtained provided that the low-temperature fluorescence spectra display well-resolved bands for the twisted conformers. Accordingly, the absorption and fluorescence spectra (Fig. 5) and the fluorescence decay curves (Fig. 6) of 2-5 in MTHF in the temperature range of $80-300 \mathrm{~K}$ have been recorded at an interval of $20 \mathrm{~K}$ [36]. It should be noted that the fluorescence spectra were collected by selective excitation of mainly the twisted conformers at a wavelength near the blue edge of the absorption band (i.e., $302 \mathrm{~nm}$ ). In addition, the temperature-dependent spectra but not the fluorescence lifetimes of $\mathbf{2}$ have been previously reported [26]. For the purpose of better comparison, the spectra of $\mathbf{2}$ are also presented in Fig. 5 along with those for 3-5.

Since the low-energy part of the absorption spectra (>345 nm) results from the planar conformers (vide supra), its weight in the absorption band of $290-370 \mathrm{~nm}$ could be a simple guideline for judging the temperature effect on the distribution of conformers in $S_{0}$. For 2 , lowering the temperature reduces the population of the planar form, as evidenced by the decreased intensity of the 354-nm band along with the increased intensity of the blue side around $310 \mathrm{~nm}$. An opposite behavior is displayed by $\mathbf{5}$, which displays a new long-wavelength band at $362 \mathrm{~nm}$ and a slight reduction in intensity for the blue side of the absorption profile upon lowering the temperature. On the other hand, compound 3 displays a twostaged absorption response to temperature. From 300 to $120 \mathrm{~K}$, it behaves in a way similar to $\mathbf{5}$ (i.e., an increase of the planar form), but it is more like the case of $\mathbf{2}$ (i.e., a decrease of the planar form) from 120 to $80 \mathrm{~K}$. Since the glass transition temperature for MTHF is $137 \mathrm{~K}$, it appears that the planar conformer of $\mathbf{3}$ is very sensitive to the environment, particularly the fluidity of the solvent molecules. In the case of $\mathbf{4}$, the structureless absorption profile observed at room temperature remains and is slightly blue-shifted at lower temperatures, indicating that the planar form of $\mathbf{4}$ is rather unfavorable in $\mathrm{S}_{0}$. Indeed, among $\mathbf{2}^{\prime}-\mathbf{5}^{\prime}$ the planar form of $\mathbf{4}^{\prime}$ is the one most away from the calculated energy minimum (Fig. 2).

According to our previous studies on 2 [26], the temperaturedependent fluorescence spectra in Fig. 5 could provide a direct clue about the relative efficiency of the excited-state planarization

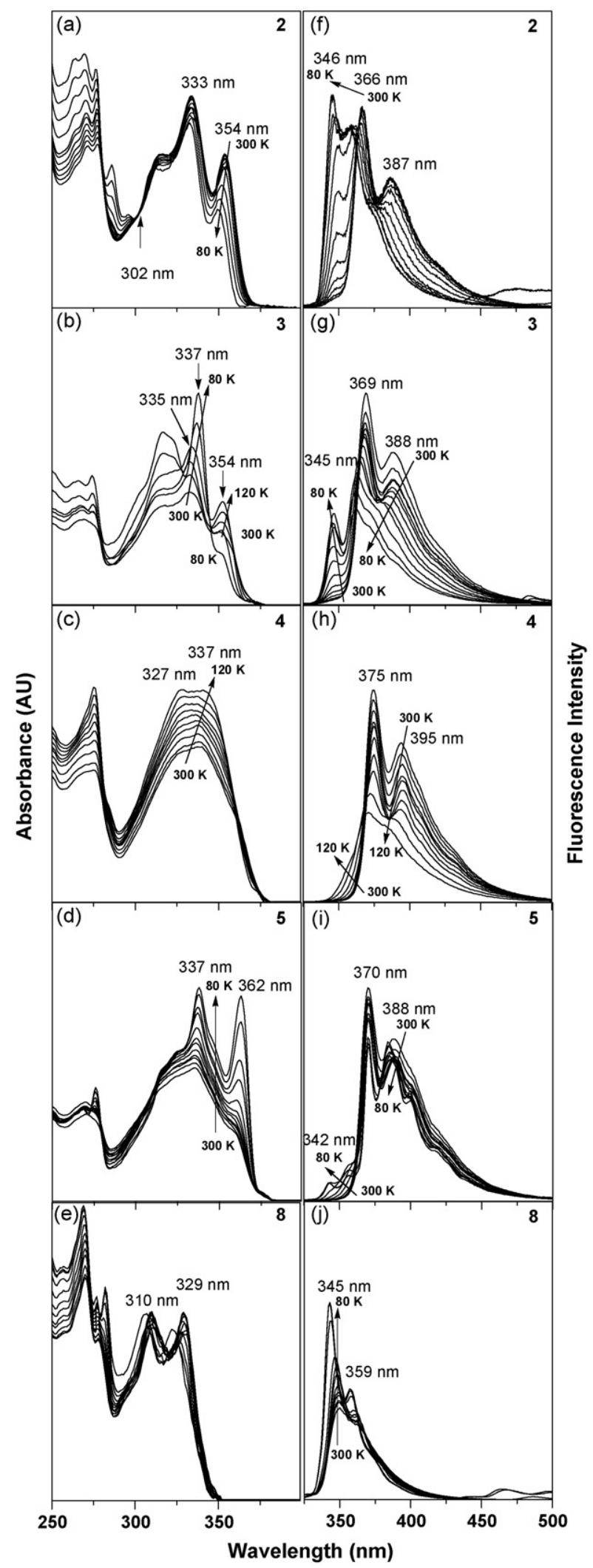

Fig. 5. Temperature dependence of $(a-e)$ absorption and $(f-j)$ fluorescence spectra $\left(\lambda_{\mathrm{ex}}=302 \mathrm{~nm}\right)$ for $(\mathrm{a}, \mathrm{f}) \mathbf{2},(\mathrm{b}, \mathrm{g}) \mathbf{3},(\mathrm{c}, \mathrm{h}) \mathbf{4},(\mathrm{d}, \mathrm{i}) \mathbf{5}$, and $\mathbf{8}(\mathrm{e}, \mathrm{j})$ in MTHF at 20-K intervals, respectively, between 80 and $300 \mathrm{~K}$. 


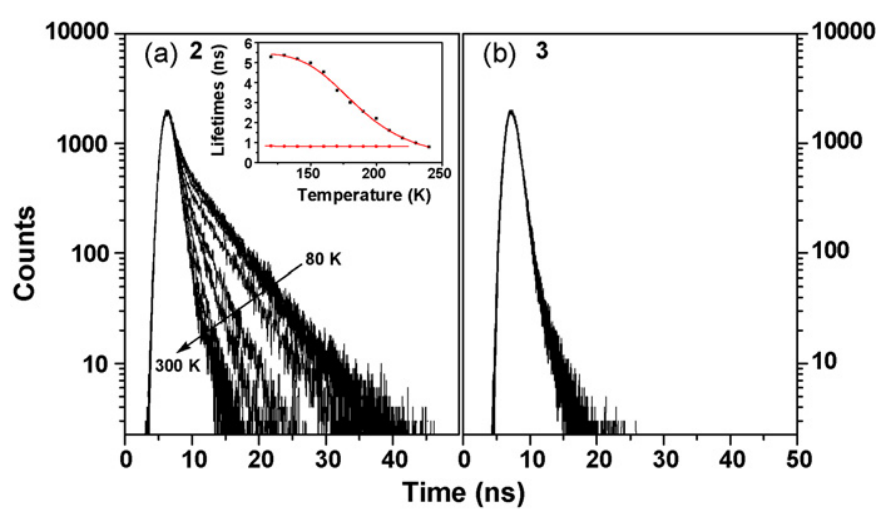

Fig. 6. Temperature dependence of the fluorescence decay curves and lifetimes for (a) $2\left(\lambda_{\text {ex }}=337 \mathrm{~nm} ; \lambda_{\text {em }}=368 \mathrm{~nm}\right)$ and (b) $3\left(\lambda_{\text {ex }}=330 \mathrm{~nm} ; \lambda_{\text {em }}=368 \mathrm{~nm}\right)$ in MTHF at $20-\mathrm{K}$ intervals between 80 and $300 \mathrm{~K}$. Inset shows both the temperature-dependent and temperature-independent fluorescence lifetimes and the nonlinear fits of the former data to Eq. (1).

reaction for the twisted conformers of $\mathbf{2 - 5}$. More specifically, the $366-\mathrm{nm}$ band for the spectrum of $\mathbf{2}$ at $300 \mathrm{~K}$ has been assigned to the $0-0$ band of the planar form and the $346-\mathrm{nm}$ band at $80 \mathrm{~K}$ to that of the twisted conformers. Thus, the relative intensity of the $80-\mathrm{K}$ vs the $300-\mathrm{K} 0-0$ band $\left(I_{80} / I_{300}\right)$ upon calibration with the absorbance would be an indication of the inhibition power of the solvent glass on the excited-state planarization relaxation of $\mathbf{2 - 5}$. In other words, the more efficient is the planarization reaction, the smaller is the ratio of $I_{80} / I_{300}$, which is $\mathbf{2}>\mathbf{3}>\mathbf{4}-\mathbf{5}$. The significant reduction in the 346-nm band on going from $\mathbf{2}$ to $\mathbf{3}$ would also indicate a large decrease in their planarization barrier $E_{\mathrm{a}}$. The emission from the twisted conformers is further reduced and the $0-0$ band is poorly defined for both $\mathbf{4}$ and $\mathbf{5}$. It should be noted that at $300 \mathrm{~K}$ there still exists some residual emission from the twisted conformers in the cases of $\mathbf{2}$ and 3. In addition, phosphorescence is observed for $\mathbf{2}$ and $\mathbf{3}$ in the solvent glass with an intensity $\mathbf{2}>\mathbf{3}$ but it is negligible for 4 and $\mathbf{5}$. The phosphorescence is weaker for the same compound upon excitation at longer wavelengths, where the excited species consists of more of the planar conformers. Evidently, the twisted conformers have larger phosphorescence quantum efficiency.

Among 2-5, only 2 displays a significant dependence of the decay profiles on temperature. Fig. 6 shows the two typical results represented by $\mathbf{2}$ and $\mathbf{3}$. The decay profiles for $\mathbf{2}$ at temperatures lower than $240 \mathrm{~K}$ are biexponential, where one of the lifetimes is nearly constant $(0.7 \pm 0.1 \mathrm{~ns})$ over the range of temperatures and the other becomes longer with increased weight at lower temperatures. The former and the latter can be attributed to the planar and the twisted conformers, respectively. Nonlinear fitting of the temperature-dependent data leads to a planarization barrier of $3.0 \mathrm{kcal} / \mathrm{mol}$ with a preexponential factor of $5.4 \times 10^{11}$. This planarization barrier is much larger than the prediction $(0.47 \mathrm{kcal} / \mathrm{mol}$ for the central-ring rotation) of the ZINDO calculation (Fig. 2a). The fitting-derived rate constants $(\Sigma k)$ for the nonactivated processes is $1.81 \times 10^{8}$, which is somewhat larger than the fluorescence rate constant $1.20 \times 10^{8}$ obtained from the fluorescence quantum yield and lifetimes. Thus, other nonactivated decay processes are also present. As indicated by the observation of phosphorescence at low temperatures, the intersystem crossing toward the triplet states might be responsible.

Another parameter needed for the evaluation of the excitedstate phenylene torsional barrier for $\mathbf{2}$ is the difference in the ground-state energy between the twisted and the planar conformer $\left(E_{\mathrm{pt}}\right)$. However, the current experimental data do not allow us to retrieve this information. In this context, a value of $1.0 \mathrm{kcal} / \mathrm{mol}$ for $E_{\mathrm{pt}}$ as suggested by the AM1 calculations (vide supra) is thus adopted $[26,37]$. The resulting excited-state phenylene torsional barrier for 2 is ca. $8.5 \mathrm{kcal} / \mathrm{mol}$ [38]. This value is larger than the calculated value $3.5 \mathrm{kcal} / \mathrm{mol}$ (the central-ring torsion, Fig. 2a) by as much as $5.0 \mathrm{kcal} / \mathrm{mol}$. Thus, it appears that the ZINDO method underestimates the excited-state torsional barrier. Indeed, in a recent report on the excited-state torsional barrier for the diethoxy substituted 1,4-bis(phenylethynyl)benzene 10 the ZINDO method led to a smaller value $(9.9 \mathrm{kcal} / \mathrm{mol})$ than the TDDFT method (15 kcal/mol) [19]. Another important and probably the dominant factor that is responsible for the discrepancy between the calculated and experimental values is the neglected solvent-rotor frictions in the gas-phase calculation. The paddlewheel-shaped pentiptycene group is expected to encounter significant resistance during rotation in solutions, and the magnitude of resistance should be larger in more viscous solvents. Since lowering the temperature of solutions also increases the solvent viscosity, the determined experimental value might reflect the torsional barrier in MTHF at low temperatures more than at room temperature.

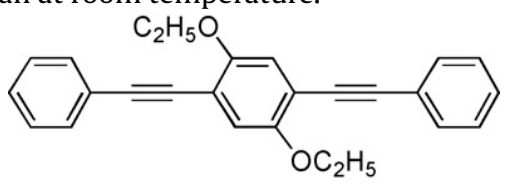

10

Unlike the case of 2, the fluorescence decays of 3-5 are essentially monoexponential at all temperatures and the lifetimes are nearly temperature independent. The absence of the temperaturedependent lifetime data and thus the information about the planarization barriers for 3-5 precludes further experimental analysis of their excited-state phenylene torsional barriers in terms of Eq. (2). Nonetheless, a minor component with a lifetime of 1.0, 2.4, and $2.5 \mathrm{~ns}$ can be deconvoluted for $\mathbf{3 , 4}$, and 5, respectively, at $80 \mathrm{~K}$ when the emission wavelength was monitored at the blue edge of the spectra (i.e., below $350 \mathrm{~nm}$ ). Provided that the minor component corresponds to the twisted conformers, the lifetimes are much shorter than that for $\mathbf{2}(5.5 \mathrm{~ns})$, consistent with the more efficient planarization relaxation processes for 3-5. Remind that the calculated excited-state phenylene torsional barrier is larger for $\mathbf{3}^{\prime}-\mathbf{5}^{\prime}$ vs $\mathbf{2}^{\prime}$ (Fig. 2) and that the calculated value for the parent compound $\mathbf{1}$ is even larger $(\sim 10 \mathrm{kcal} / \mathrm{mol})$ [15]. If these calculations are correct, the excited-state torsional barrier is lower for those with bulkier substituents due to destabilization of the planarized conformations.

\subsection{Twisted conformations}

To identify the structural nature of the twisted conformers of $\mathbf{2}$ that is responsible for the observed fluorescence at low temperatures, we have carried out the same spectroscopic investigation of three model compounds 6-8. As illustrated in Scheme 1, the PE conjugated backbone in $\mathbf{2}$ would contain two different de-conjugated moieties, corresponding to segments $\mathbf{6}$ and 7, if the geometry of the PE backbone is 1-twisted-a-like (i.e., 2-twisted-a). In contrast, it would contain the segments $\mathbf{6}$ and $\mathbf{8}$ if the twisted form is $\mathbf{1}$-twistedb-like (i.e., 2-twisted-b). Thus, comparison of the photophysical behavior of the twisted form of $\mathbf{2}$ with that of $\mathbf{6 - 8}$ should be informative.

Table 2 shows the photophysical data of $\mathbf{2}$ and 6-8 in MTHF at 80,140 , and $300 \mathrm{~K}$. For compounds 6 and 7, lowering the temperature leads to a slight sharpening but nearly no shift of the $0-0$ absorption band and a small blue shift $(\sim 7 \mathrm{~nm})$ of the fluorescence spectra (spectra not shown). Since both $\mathbf{6}$ and $\mathbf{7}$ are free of rotational conformers, the blue shift can be attributed to changes in the rates of solvent relaxation. The temperature effect on the fluorescence lifetimes is essentially negligible. Both the absorption and fluorescence spectra are more red-shifted for $\mathbf{7}$ vs $\mathbf{6}$, which suggest that energy transfer could occur from the segment $\mathbf{6}$ to the 
Table 2

Photophysical data of compounds 2 and 6-8 in 2-methyltetrahydrofuran (MTHF) at 80, 140, and $300 \mathrm{~K}$.

\begin{tabular}{|c|c|c|c|c|c|c|}
\hline Compound & $\mathrm{T}(\mathrm{K})$ & $\lambda_{\mathrm{abs}}(\mathrm{nm})^{\mathrm{a}}$ & $\lambda_{\text {ex }}(\mathrm{nm})^{\mathrm{b}}$ & $\lambda_{\mathrm{fl}}(\mathrm{nm})$ & $\tau_{\mathrm{fl}}(\mathrm{ns})$ & $\Phi_{\mathrm{fl}}$ \\
\hline 2 & $\begin{array}{l}80 \\
140 \\
300\end{array}$ & $\begin{array}{l}333 \\
333(352) \\
334(354)^{c}\end{array}$ & $\begin{array}{l}302 \\
302 \\
302\end{array}$ & $\begin{array}{l}346(358) \\
348(359) \\
366(387)^{c}\end{array}$ & $\begin{array}{l}5.5 \\
0.7,5.2 \\
0.7^{c}\end{array}$ & $0.63^{\mathrm{d}}$ \\
\hline 6 & $\begin{array}{l}80 \\
140 \\
300\end{array}$ & $\begin{array}{l}306(295) \\
306(295) \\
307(296)\end{array}$ & $\begin{array}{l}290 \\
290 \\
290\end{array}$ & $\begin{array}{l}310(322) \\
313(324) \\
316\end{array}$ & $\begin{array}{l}6.3 \\
6.0 \\
6.0\end{array}$ & $0.59^{\mathrm{e}}$ \\
\hline 7 & $\begin{array}{l}80 \\
140 \\
300\end{array}$ & $\begin{array}{l}331 \\
331 \\
330\end{array}$ & $\begin{array}{l}317 \\
317 \\
317\end{array}$ & $\begin{array}{l}337(351) \\
341(353) \\
344\end{array}$ & $\begin{array}{l}5.5 \\
5.6 \\
6.0\end{array}$ & $0.82^{f}$ \\
\hline 8 & $\begin{array}{l}80 \\
140 \\
300\end{array}$ & $\begin{array}{l}322(305) \\
328(309) \\
329(310)\end{array}$ & $\begin{array}{l}302 \\
302 \\
302\end{array}$ & $\begin{array}{l}345(359) \\
349(362) \\
352\end{array}$ & $\begin{array}{l}5.6 \\
5.6 \\
4.5\end{array}$ & $0.58^{\mathrm{f}}$ \\
\hline
\end{tabular}

\footnotetext{
a The second vibronic band or shoulder is given in parentheses.

b Excitation wavelength for fluorescence spectra and lifetimes.

c From ref. [26].

d $\lambda_{\text {ex }}=338 \mathrm{~nm}$.

e $\lambda_{\text {ex }}=290 \mathrm{~nm}$.

f $\lambda_{\mathrm{ex}}=323 \mathrm{~nm}$.
}

segment $\mathbf{7}$ in 2-twisted-a and thus the segment $\mathbf{7}$ would dominate the emission due to its lower energy state. It is interesting to note that the photophysical properties of 7, particularly the fluorescence lifetime and the $0-0$ absorption band, are very similar to those of the twisted form of $\mathbf{2}$. In the case of the two-ring system $\mathbf{8}$, the temperature effect on the absorption spectra is significant, where the $0-0$ band intensity at $329 \mathrm{~nm}$ decreases and new blue-shifted bands at 322 and $305 \mathrm{~nm}$ grow up upon lowering the temperature (Fig. 5e). Apparently, like the cases of $\mathbf{2}$ and 3, the population of the twisted conformers of $\mathbf{8}$ increases at low temperatures. However, unlike the cases of $\mathbf{2}$ and $\mathbf{3}$, the fluorescence spectra show only a small blue shift $(\sim 7 \mathrm{~nm})$ at $80 \mathrm{vs} 300 \mathrm{~K}$ (Fig. $5 \mathrm{j}$ ). In conjunction with the facts that (a) the fluorescence lifetime decreases upon raising the temperature and that (b) at $80 \mathrm{~K}$ the fluorescence lifetime of 8 is again the same as that of $\mathbf{2}$ and $\mathbf{7}$, we conclude that the fluorescence of 8 at $80 \mathrm{~K}$ is dominated by the unrelaxed twisted conformers, which contain segments 6 and 7. Since the calculated rotational potentials for $\mathbf{8}$ (figure not shown) are very similar to those for $\mathbf{2}$ with the external-ring rotation (i.e., $\chi_{2}$, Fig. $2 a$ ) with an inherent planarization barrier of $0.17 \mathrm{kcal} / \mathrm{mol}$, the restriction of rotation for the twisted form of $\mathbf{8}$ at $80 \mathrm{~K}$ is mainly due to the large rotational friction of the bulky pentiptycene ring. It should be noted that these data were obtained with photoexcitation at the wavelengths that mainly the twisted species absorb. In the case of $\mathbf{2}$, the excited twisted species could be 2-twisted-a and 2-twisted-b, and thus both species could contribute to the observed 346-nm emission band for $\mathbf{2}$ at $80 \mathrm{~K}$ with the emitter being segments $\mathbf{7}$ and $\mathbf{8}$, respectively. Nonetheless, this does not affect the two-state (twisted vs planar) model discussed in Fig. 1, as the planarization relaxation from either twisted form differs only in the ring that rotates. It is the central-ring for 2-twisted-a but the external-ring for 2twisted-b. Since the calculations (Fig. 2a) suggest that the inherent planarization barrier might not be the same for the two forms, the experimental value could be considered as an average one.

\section{Conclusion}

The dependence of the ground-state distribution of rotational conformers and the excited-state phenylene torsional barriers for $p$-phenyleneethynylene (PE) systems on the substituents has been demonstrated based on the pentiptycene-derived 1,4bis(phenylethynyl)benzenes 2-5. Whereas there is only one emitting species for all cases at room temperature due to fast excited-state planarization relaxation for the twisted conformers, emission from the structurally unrelaxed twisted conformers are present in the MTHF glass at $80 \mathrm{~K}$. The efficiency of planarization relaxation is in the order $\mathbf{2}<\mathbf{3}<\mathbf{4 - 5}$, consistent with the decreased trend in the bulkiness of the central-ring substituents and thus the inherent planarization barrier (minor factor) and the rotational frictions in solutions (major factor). The unique substituent effect in 2 leads to a narrower conformer distribution in $S_{0}$ and $S_{1}$. The well-resolved fluorescence spectra and lifetimes for the twisted conformers of $\mathbf{2}$ at low temperatures provide a unique opportunity for experimental evaluation of the barriers for the planarization relaxation and phenylene torsions in the singlet excited-state. On the basis of the model compounds $\mathbf{6 - 8}$, the geometry of the conjugated backbone in the fluorescent twisted form of 2 at $80 \mathrm{~K}$ is similar to 1-twisted-a and 1-twisted-b (Scheme 1), and the fluorescence is from the segments $\mathbf{7}$ and $\mathbf{8}$, respectively. The phenomenon of excitation wavelength-dependent fluorescence quantum yield for 2-5 indicates that the planar conformers are inherently stronger fluorescent than the twisted form in PE systems, presumably due to less efficient intersystem crossing toward the triplet state. The information provided herein might prove of value for the design of new PE-based $\pi$ systems of the desired electronic properties.

\section{Acknowledgments}

We thank the National Science Council, Academia Sinica, and National Taiwan University for financial support. The computing time granted by the National Center for High-Performance Computing is also acknowledged.

\section{References}

[1] Q. Zhou, T.M. Swager, J. Am. Chem. Soc. 117 (1995) 7017-7018.

[2] Q. Zhou, T.M. Swager, J. Am. Chem. Soc. 117 (1995) 12593-12602.

[3] J.-S. Yang, T.M. Swager, J. Am. Chem. Soc. 120 (1998) 5321-5322.

[4] J.-S. Yang, T.M. Swager, J. Am. Chem. Soc. 120 (1998) 11864-11873.

[5] T.M. Swager, Acc. Chem. Res. 31 (1998) 201-207.

[6] J. Zheng, T.M. Swager, Adv. Polym. Sci. 177 (2005) 151-179.

[7] U.H.F. Bunz, Chem. Rev. 100 (2000) 1605-1644.

[8] C. Schmitz, P. Pösch, M. Thelakkat, H.-W. Schmidt, A. Montali, K. Feldman, P. Smith, C. Weder, Adv. Funct. Mater. 11 (2001) 41-46.

[9] E. Arias, T. Maillou, I. Moggio, D. Guillon, J. Le Moigne, B. Geffroy, Synth. Met. 127 (2002) 229-231.

[10] C.A. Breen, J.R. Tischler, V. Bulović, T.M. Swager, Adv. Mater. 17 (2005) 1981-1985.

[11] S.A. McFarland, N.S. Finney, J. Am. Chem. Soc. 124 (2002) 1178-1179.

[12] G. Brizius, K. Billingsley, M.D. Smith, U.H.F. Bunz, Org. Lett. 5 (2003) 3951-3954

[13] B.C. Englert, M.D. Smith, K.I. Hardcastle, U.H.F. Bunz, Macromolecules 37 (2004) 8212-8221. 
[14] M. Levitus, M.A. Garcia-Garibay, J. Phys. Chem. A 104 (2000) 8632-8637.

[15] M. Levitus, K. Schmieder, H. Ricks, K.D. Shimizu, U.H.F. Bunz, M.A. GarciaGaribay, J. Am. Chem. Soc. 123 (2001) 4259-4265.

[16] M. Levitus, G. Zepeda, H. Dang, C. Dodinez, T.-A.V. Khuong, K. Schmieder, M.A. Garcia-Garibay, J. Org. Chem. 66 (2001) 3188-3195.

[17] A. Beeby, K. Findlay, P.J. Low, T.B. Marder, J. Am. Chem. Soc. 124 (2002) 8280-8284.

[18] S.J. Greaves, E.L. Flynn, E.L. Futcher, E. Wrede, D.P. Lydon, P.J. Low, S.R. Rutter, A. Beeby, J. Phys. Chem. A 110 (2006) 2114-2121.

[19] P.V. James, P.K. Sudeep, C.H. Suresh, K.G. Thomas, J. Phys. Chem. A 110 (2006) 4329-4337.

[20] T. Miteva, L. Palmer, L. Kloppenburg, D. Neher, U.H.F. Bunz, Macromolecules 33 (2000) 652-654.

[21] M.I. Sluch, A. Godt, U.H.F. Bunz, M.A. Berg, J. Am. Chem. Soc. 123 (2001) 6447-6448.

[22] J. Kim, T.M. Swager, Nature 411 (2001) 1030-1034.

[23] Q. Chu, Y. Pang, Macromolecules 36 (2003) 4614-4618.

[24] L.T. Liu, D. Yaron, M.I. Sluch, M.A. Berg, J. Phys. Chem. B 110 (2006) 18844-18852.

[25] L.T. Liu, D. Yaron, M.A. Berg, J. Phys. Chem. C 111 (2007) 5770-5782.

[26] J.-S. Yang, J.-L. Yan, C.-Y. Hwang, S.-Y. Chiou, K.-L. Liau, H.-H.G. Tsai, G.-H. Lee, S.-M. Peng, J. Am. Chem. Soc. 128 (2006) 14109-14119.

[27] F.D. Lewis, X. Zuo, J. Am. Chem. Soc. 125 (2003) 2046-2047.

[28] F.D. Lewis, X. Zuo, J. Am. Chem. Soc. 125 (2003) 8806-8813.

[29] J.-S. Yang, K.-L. Liau, C.-Y. Hwang, C.-M. Wang, J. Phys. Chem. A 110 (2006) 8003-8010.

[30] V.E. Williams, T.M. Swager, Macromolecules 33 (2000) 4069-4073.

[31] W.R. Dawson, M.W. Windsor, J. Phys. Chem. 72 (1968) 3251-3260.

[32] M.J.S. Dewar, E.G. Zoebisch, E.F. Healy, J.J.P. Stewart, J. Am. Chem. Soc. 107 (1985) 3902-3909.

[33] M.C. Zerner, G.H. Leow, R.F. Kirchner, U.T. Mueller-Westerhoff, J. Am. Chem. Soc. 102 (1980) 589-599.
[34] Gaussian 03, Revision B.03, M.J. Frisch, G.W. Trucks, H.B. Schlegel, G.E. Scuseria, M.A. Robb, J.R. Cheeseman, J.A.Jr. Montgomery, T. Vreven, K.N. Kudin, J.C. Burant, J.M. Millam, S.S. Iyengar, J. Tomasi, V. Barone, B. Mennucci, M. Cossi, G. Scalmani, N. Rega, G. A. Petersson, H. Nakatsuji, M. Hada, M. Ehara, K. Toyota, R. Fukuda, J. Hasegawa, M. Ishida, T. Nakajima, Y. Honda, O. Kitao, H. Nakai, M. Klene, X. Li, J.E. Knox, H.P. Hratchian, J.B. Cross, C. Adamo, J. Jaramillo, R. Gomperts, R.E. Stratmann, O. Yazyev, A.J. Austin, R. Cammi, C. Pomelli, J.W. Ochterski, P.Y. Ayala, K. Morokuma, G.A. Voth, P. Salvador, J.J. Dannenberg, V.G. Zakrzewski, S. Dapprich, A.D. Daniels, M.C. Strain, O. Farkas, D.K. Malick, A.D. Rabuck, K. Raghavachari, J.B. Foresman, J.V. Ortiz, Q. Cui, A.G. Baboul, S. Clifford, J. Cioslowski, B.B. Stefanov, G. Liu, A. Liashenko, P. Piskorz, I. Komaromi, R.L. Martin, D.J. Fox, T. Keith, M.A. Al-Laham, C.Y. Peng, A. Nanayakkara, M. Challacombe, P.M.W. Gill, B. Johnson, W. Chen, M.W. Wong, C. Gonzalez, J.A. Pople, Gaussian, Inc., Pittsburgh PA, 2003.

[35] It should be noted that the octyl group is more electron-donating than the methyl groups, which might result in somewhat different local charges on the attached phenyl rings in $\mathbf{2 - 5}$ vs $\mathbf{2}^{\prime} \mathbf{- 5}$. However, such a difference should have negligible influence in the rotational potential due to their symmetric, linear, and nonpolar nature of the conjugated backbone. The calculated ground-state dipole moments for $\mathbf{2}^{\prime}-\mathbf{5}^{\prime}$ in both their planar and twisted forms are all near $0.0 \mathrm{D}$.

[36] The temperature range for $\mathbf{4}$ is $120-300 \mathrm{~K}$ because of stronger light scattering at temperatures lower than $120 \mathrm{~K}$.

[37] A value of $E_{\mathrm{pt}}=1 \mathrm{kcal} / \mathrm{mol}$ corresponds to a population ratio of $5: 1$ for the planar:twisted conformers, which is not unreasonable in considering the relative intensity of the vibrational bands in the absorption spectra of 2.

[38] The validity of using Eq. (2) for the determination of the excited-state phenylene torsional barrier requires that the transition state for the planarization is also the energy maximum of the excited-state potential energy surface. If this is not the case, the torsional barrier would be larger than $8.5 \mathrm{kcal} / \mathrm{mol}$. 